\title{
Visual Programming Tools Implementation for Educational Cultural Heritage Promotion
}

\author{
Eleni Moustaka, and Antonia Plerou
}

\begin{abstract}
Nowadays, mobile devices are considered to be a powerful and portable tool for assisting people dealing with daily life issues. With the advance of mobile technology, the issue of mobile learning has been broadly explored in elearning research. Several researchers and educators use pedagogical and technical strengths of mobile technology into learning environments. In this paper, an educational mobilebased application is described in order to promote Corfu's Old town cultural heritage. The proposed educational mobile based application was pilot-tested in forty-five postgraduate students at Ionian University during cultural heritage courses. The students used a mobile-based educational environment in order to augment their heritage cultural perception and knowledge. The case study results suggest an enhanced perception of the educational content as well as a significantly increased acceptance of the education approach within the role of mobile technology in higher education.
\end{abstract}

Index Terms-Adult Learning; Mobile Learning; Cultural Heritage; Mobile Applications.

\section{INTRODUCTION}

During last decades, smart mobile devices (tablets, cell phones) use is spread to a broad variety of the population, regardless of age or economic level [1]. The rapid progress of smart mobile phones allows users to install and use applications according to their needs and interests [2]. Numerous applications for smart mobile devices are related to education since mobile technology provides an innovative type of learning. Within these applications, learners have access to information anytime and anywhere in order to perform authentic activities in the context of learning procedure [3]. The objective of this study is to evaluate the effect of mobile learning in postgraduate student's educational achievement and analyze their attitude towards this mobile-based educational approach

. The research questions addressed were:

- Does the use of mobile-based educational applications significantly improve postgraduate student's educational achievement?

- Does the use of mobile-based educational applications significantly improve postgraduate student's attitude towards learning?

In the present study, forty-five postgraduate students enrolled in cultural heritage courses at an M.Sc. program of the Department of Archives, Library Science and

Published on February 2018.

E. Moustaka is with Department of Archives, Library Science, and Museology, Ionian University, Corfu (e-mail: 114mous@ionio.gr)

A. Plerou is with Bioinformatics and Human Electrophysiology Laboratory, Department of Informatics, Ionian University, Corfu, (e-mail tplerou@ionio.gr)
Museology of Ionian University, participated in the study. The case study participants were selected with the use of random sampling, among the M.Sc. program courses students, within the frame of sampling theory [4]. Participants were assigned to the educational mobile application named $\mathrm{C}-\mathrm{o}-\mathrm{C}$ (Cisterns of Corfu) under the instruction provided during their courses. The application apk file was released with the use of World Wide Web. After the mobile-based lectures, students completed an educational achievement and attitude (user satisfaction) survey. The analysis of the results of educational efficiency and user satisfaction after the mobile-based lectures suggest the enhanced efficiency of the mobile-based learning [5].

\section{Background}

Smart cell phones offer users a variety of upgraded services, such as web navigation, application installation, and technology of Global Positioning System (GPS) etc. Several additional features, combined with advanced memory and operating systems processing units, have converted smart mobile devices into small computers [6]. Smart mobile devices provide access to hundreds of applications that offer services related to communication, social networking, health, education, entertainment, tourism etc. [7]. In the case of educational context of smartphones, mobile learning is promoted.

Mobile learning can be defined as "any educational provision where the sole or dominant technologies are handheld or palmtop devices" [8]. In accordance with several mobile learning aspects, the mobility of technology (1), the mobility of learning (2), and the mobility of learner (3) can be specified for this type of learning [9]. The mobility of technology (1) focuses on examining the possibility of using portable and wireless devices such as mobile phones, laptops, and tablets for educational purposes. The focus of mobility on learning (2) is the extensive use of mobile devices for learning outside of the typical classroom. The mobility of learner (3) focuses on the design or the appropriation of learning spaces and on informal learning and lifelong learning [10].

\section{Methodology}

The proposed mobile educational project is involved with analysis, design, implementation and evaluation phases. In the analysis phase, the analysis of the special needs of the educational project was essential. In particular, the objective of educational application and the target group of the educated participants was taken into consideration. Furthermore, the hardware and software selection was vital. In the design phase, a relative literature review was crucial 
as well as the educational material collection (photo shooting) and material processing. Additionally, the aesthetic design of the educational application was crucial. During the implementation phase, the visual material (images, informational text etc.) is incorporated. In the evaluation phase, the validation of the application in terms of usability (user's satisfaction) and educational efficacy (educational achievement level) was conducted with the use of a web spread survey [11].

\section{A. Phase 1: Analysis}

The initial phase is focused on the analysis of the basic educational project objectives and requirements. A primary need is to determine the educational objective and select the informational material involved in the educational mobile application. The basic objective is to enlighten and endorse Corfu's Old Town cultural heritage within the frame of educational aspects. The material research was mainly based on information retrieved from local journals, old editions of cultural books, local libraries material and online libraries. Nevertheless, the basic material was retrieved from a special edition entitled "Cisterns and Spring of Corfu" ( $« \Sigma \tau \varepsilon \dot{\rho} \rho \varepsilon \varepsilon \varsigma$

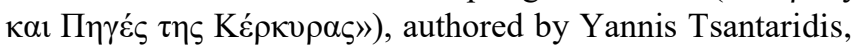
which provided essential information of Corfu's Old Town cultural point of interest [12].

\section{1) Hardware Description}

A crucial objective of the analysis of the application requirements is to select the furthermost appropriate operating system in terms of operating efficiency. The most common operating systems for portable devices are Android, iOS (iPhone), Windows Phone, BlackBerry, Symbian, etc. In the case of iOS, BlackBerry, and Windows Phone operating systems, it is noteworthy that they are only available on Apple, BlackBerry and Windows Phone devices respectively [13]. Mobile devices based on this type of operating system are limited in comparison with widespread Android operating system based devices [14]. On the other side, Android operating system (open source software) devices can be synchronized with "Google Maps" service, which is essential for the participant's navigation within the proposed application [15].

\section{2) Software Description}

An additional essential aspect in terms of application requirements analysis is to select the most suitable software for the proposed educational application implementation. Numerous software, compatible with the Android operating system, is available. Nevertheless, MIT App Inventor software, an open-source web application originally provided by Google, (now maintained by the Massachusetts Institute of Technology -MIT) was selected. App Inventor is a visual programming environment used in order to create mobile applications for mobile phones and tablets devices, based on the Android operating system. This visual programming tool is based on a user-friendly programming environment, namely on a drag-and-drop methodology, therefore no particular programming knowledge is required [16].

\section{B. Phase 2: Design}

During the application design phase, the material collection and processing procedure was essential.

\section{1) Material Collection}

The material collection process is referred to the images and the respective informational text to be incorporated in the mobile application for cultural promotion approach. Corfu's Old Town cisterns are considered to be the cultural points of interest in the proposed educational study, which are mainly selected on historical and educational criteria. A detailed presentation of them is to follow. Specifically, "Gradenigou Cistern" and "Theatrou Cistern", which are located in Spianada Square, "Vrahliotis Cistern", which is located in the homonymous Square, "Kremastis Cistern", which is located at Lillis Desilla Square and "Kardakiou Spring", which is located in the homonymous seaside in Mon Repo's area..

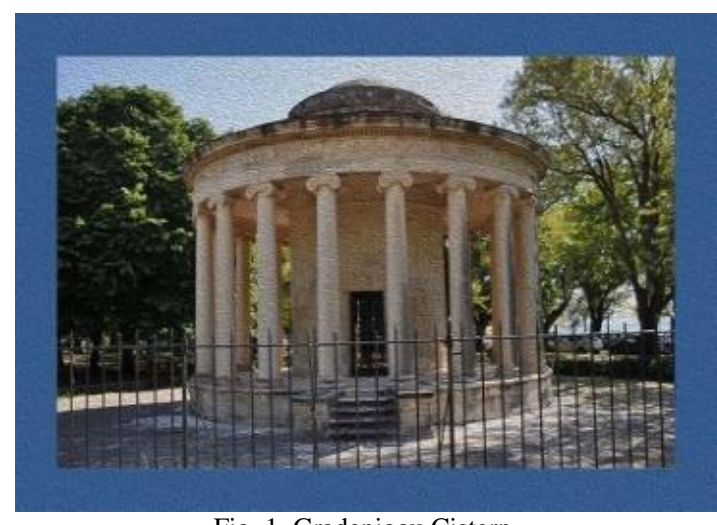

Fig. 1. Gradenigou Cistern.

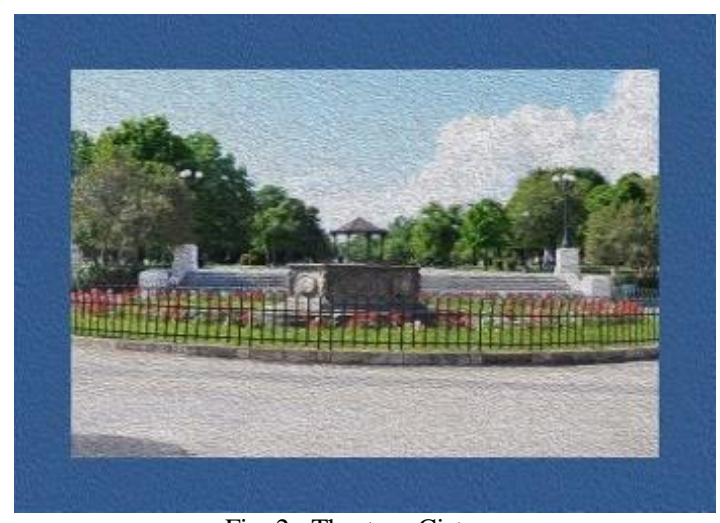

Fig. 2. Theatrou Cistern.

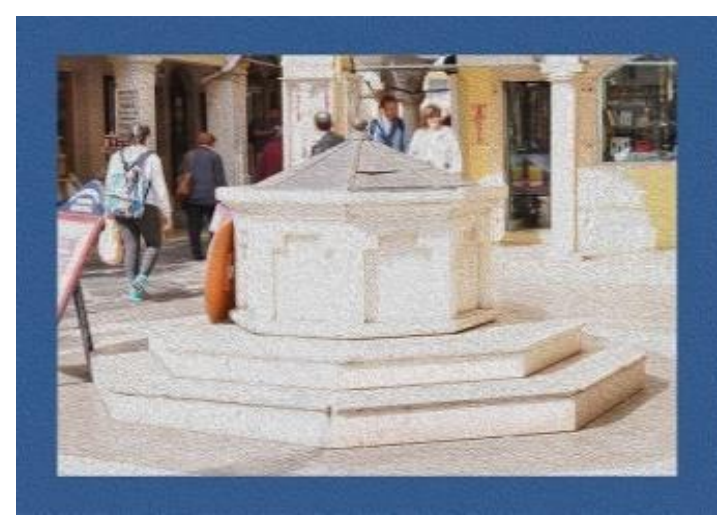

Fig. 3. Vrahlioti Cistern. 


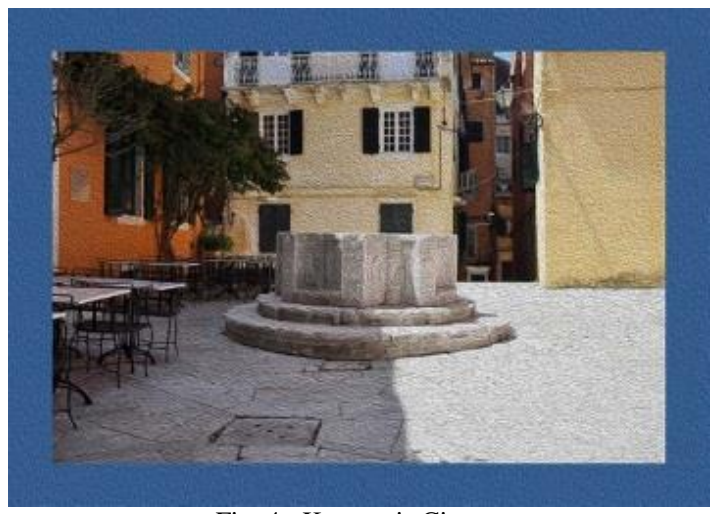

Fig. 4. Kremastis Cistern

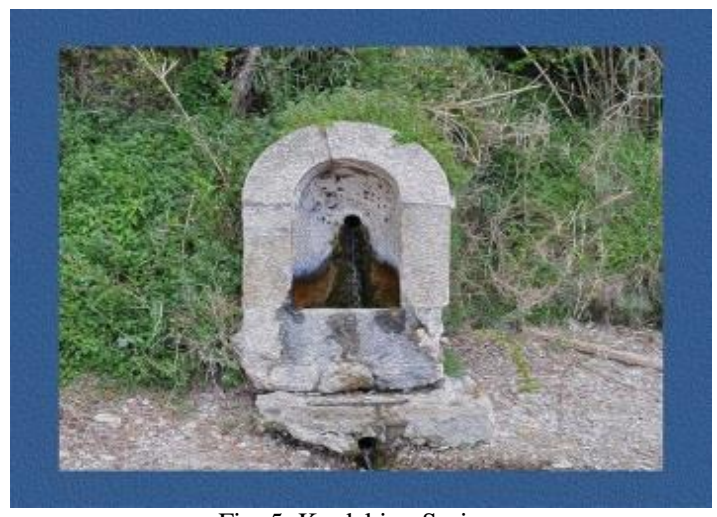

Fig. 5. Kardakiou Spring.

The visual material was obtained manually with the use of a Nikon D90 photo shooting camera parted from an 18$55 \mathrm{~mm}$ photo lens. The point of interest areas photo shooting procedure was conducted during early morning hours in order to attain the greatest image quality due to the daylight effect. After the photo shooting procedure, two photos were selected in terms of purity, brightness, and light quality. The images specifications were the best available, namely, image dimension width $\mathrm{x}$ height $4300 \times 2800$ pixels and image size 5.5 MB.

\section{2) Material Processing}

The material processing is related to the material transformation with the use of images processing tools in order to achieve an optimized aesthetic outcome for the educational environment. The snapshots obtained from Corfu's Old Town cultural points of interest proceeded with graphics editor software (Adobe Photoshop). The size of each image was reduced, and the quality of each image was enhanced in terms of brightness and image high-resolution quality. The textual information was initially proceeded with the use of a text processing software (MS Word) and was converted into an image in order to be incorporated in the $\mathrm{C}$ o-C (Cisterns of Corfu) application.

\section{Phase 3: Implementation}

The algorithmic procedure used for finalizing the structure of the educational application is presented in the flowchart in Fig. 6. The application is composed 'of several screens which are linked to each other, so users can navigate in the educational platform using the mobile's touchscreen options. The home page, displayed in Fig. 7, is consisted of a panoramic image of the Corfu's Old Town, as well as the acronym of the application C-o-C, (Cisterns of Corfu) and the application full name both in English and in Greek,

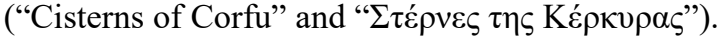
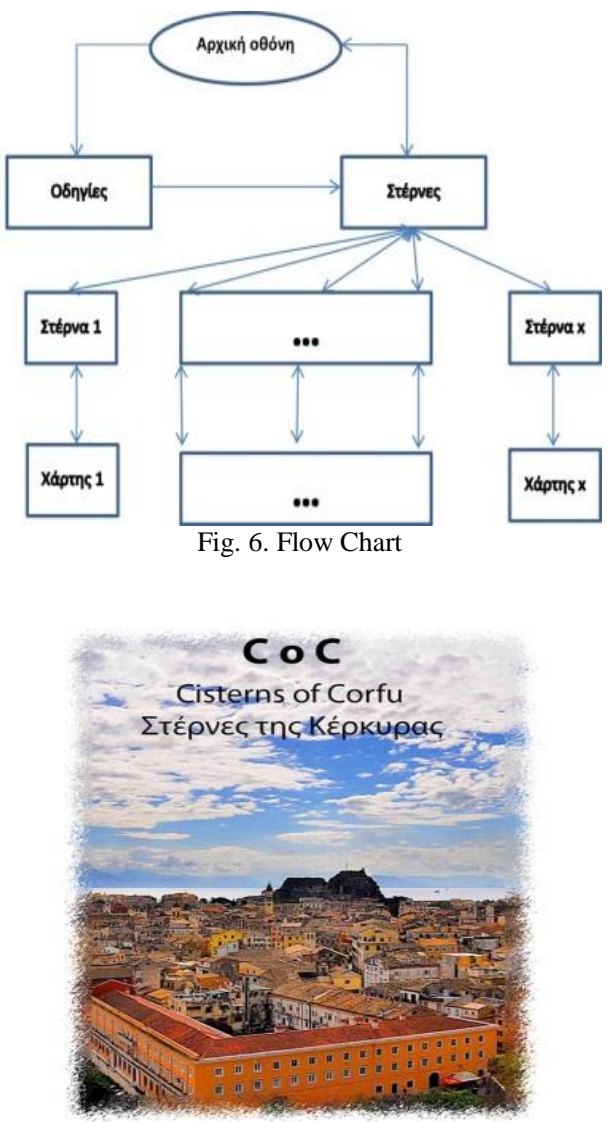

Fig. 7. Home Page

The proposed educational application consists of two different parts. One part is referred to the designer platform (Fig. 8) and the other one to the blocks based platform (Fig. 9). The application developer is able to design and preview the application output and provide the desired aesthetic result with the use of the designer platform. In the case of the block-based platform, (available in a distinct screen), the design of the application structure is managed with the use of visual programming tools (namely buttons, pictures, lists, tables etc.) Moreover, several images, different colors, and textual elements are used in order to optimize the application aesthetic result.

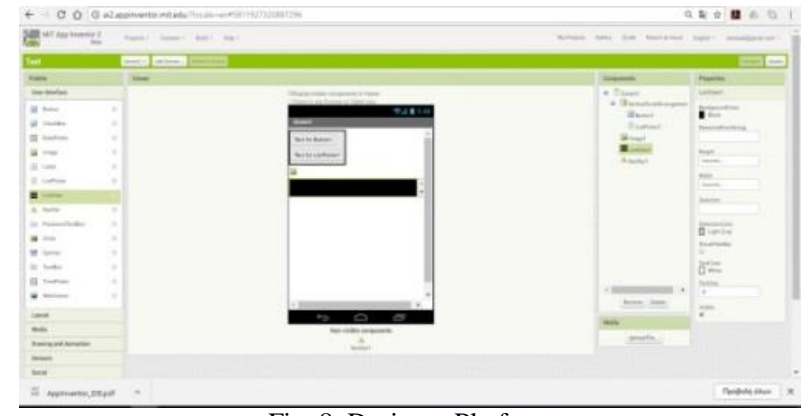

Fig. 8. Designer Platform 


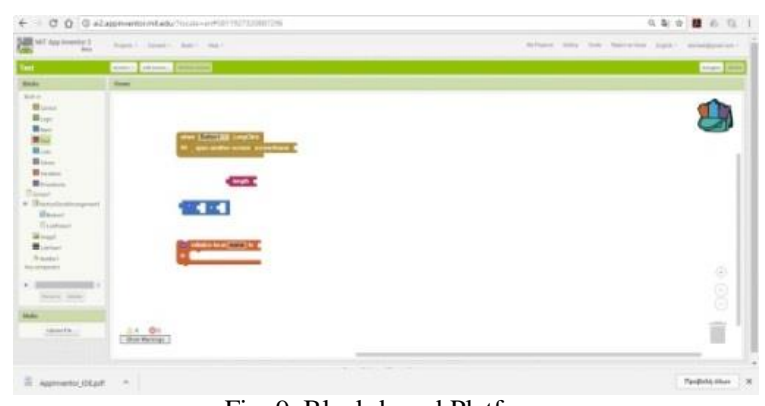

Fig. 9. Block-based Platform

Users are able to access the "instruction" screen or the "table of contents" screen directly from the home page screen. The "instructions" option provides basic navigation instructions, while "table of contents" screen provides direct accessibility to the selected points of interest. With prerequisites of World Wide Web (www) access and Global Positioning System (GPS) activation, users can navigate with the use of "Google Maps" service to the selected points of interest. While a user selects a specific image, a snapshot of the point of interest, the respective textual information, the map of the surrounded area and the ability to navigate to the point of interest are activated (Fig. 10).

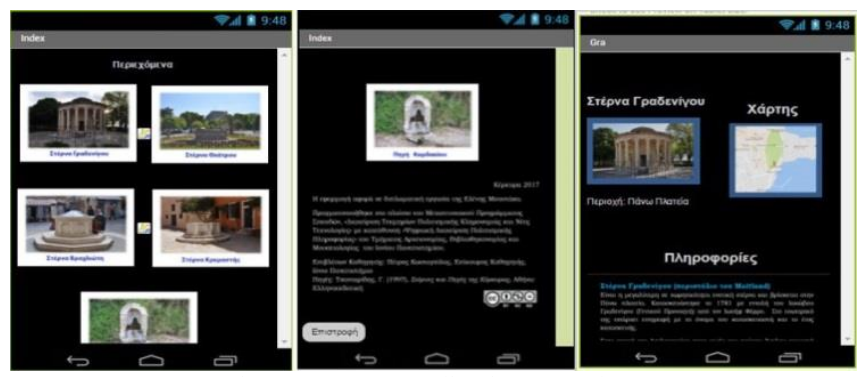

Fig.10. C-o-C Application Snapshot

\section{Phase 4: Pilot Testing Phase}

In order to evaluate the application efficacy, the forty-five students, who participate in the educational project, were asked to value the educational approach. A survey in reference to the student's aspects related to the user's satisfaction and the application's educational efficacy was conducted once the educational procedure was completed. This survey was created with "Google Form" tool and was released with the use of the World Wide Web. It was constituted of seven Likert scale questions, four binary type questions (yes/no), five open type questions and several demographic questions.

The evaluation procedure was twofold. The first part was related to the application usability and the second one to the educational efficiency in respect to the proposed learning procedure. Specifically, the first part was related to the installation and navigation potential difficulties as well as with the application's aesthetic appearance evaluation. The second part was related to the educational content efficacy and the significance of the information provided. The results suggested the enhanced user's satisfaction in both aspects and are presented in details in the next section.

\section{RESULTS}

In reference to the level of ease in the case of the installation procedure, $75 \%$ and $25 \%$ of the pilot test participants suggested that the installation of the $\mathrm{C}-\mathrm{o}-\mathrm{C}$ application was "very easy" and "easy" respectively (Fig. 11). Moreover, the navigation procedure was very easy according to the $48 \%$ of the participants and easy for the $36 \%$ of the participants (Fig. 12). In accordance with the user's satisfaction level, participants claimed that their satisfaction was really high (48\%) and high (44\%) (Fig. 13).

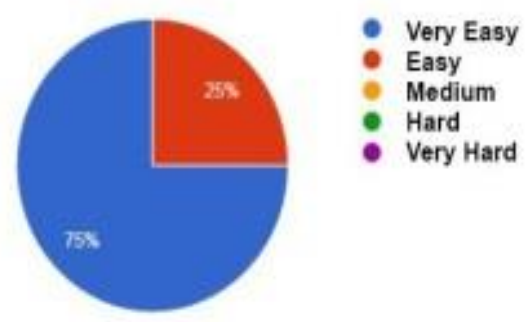

Fig. 11. C-o-C application installation ease level

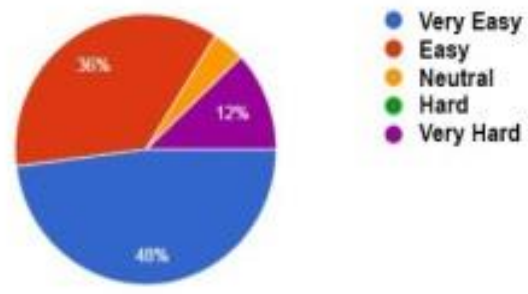

Fig. 12. C-o-C application level of navigation ease

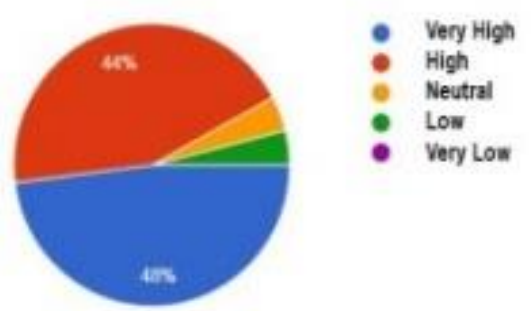

Fig. 13. C-o-C application users satisfaction level

Moreover, the level of participant's experiences in reference with the acquaintance in respect with similar applications, as well as the acceptance level of educational approach was evaluated. $92 \%$ of the participants suggested that they had used similar application in the past and that they would like to receive additional training in general with the use of mobile-based learning (Fig. 14 and 15). Moreover, they claimed that it is very likely (96\%) to suggest this application to a friend or colleague (Fig. 16). 


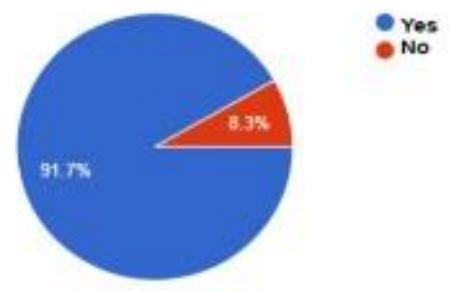

Fig. 14. C-o-C application user's experience level

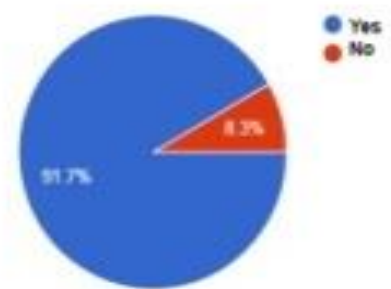

Fig. 15. C-o-C application user's acceptance level

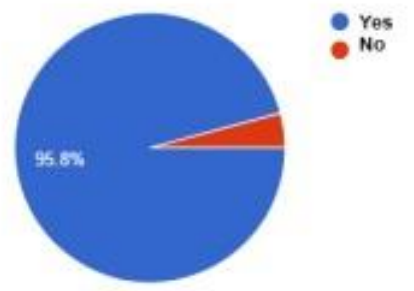

Fig. 16. Intention to suggest $\mathrm{C}-\mathrm{o}-\mathrm{C}$ application to a friend

In reference with application educational efficiency, almost the half of the participants $(48 \%)$ considered that the application was "very efficient" and $36 \%$ of them that it was an educational sufficient application (Fig. 17). In the case of the educational information provided within this application, $44 \%$ and $40 \%$ of the user's suggested that the educational content was clear, educational sufficient and easy to be understood and assimilated (Fig. 18 and 19).

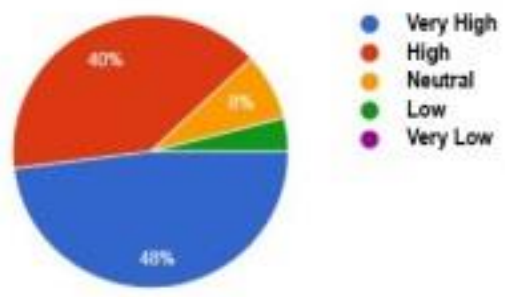

Fig. 17. C-o-C application educational efficiency level

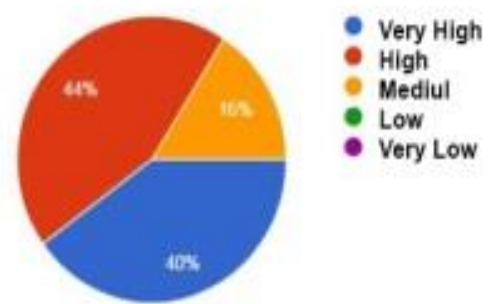

Fig. 18. Perception level of the educational information provide from C-o-C application

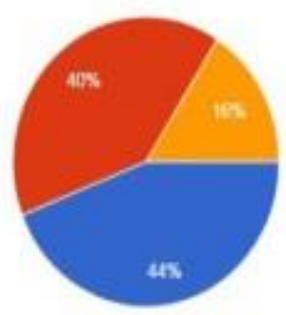

- Very High

- High

- Medium

- Hard

- Very Hard

Fig. 19. C-o-C application provided knowledge efficiency

\section{LIMITATIONS}

The pilot study evaluation suggested a number of limitations of the proposed educational application. Several students, who were selected to participate in the educational pilot study, were using a mobile device based on another operating system (i.e. iOS, Windows Phone etc.), so they had to be excluded from the study. Additionally, the C-o-C application was occasionally detected as harmful software (due to a firewall application) during the installation phase. Nevertheless, in case that the installation is proceeding within the "Play Store" platform, this limitation could be overcome.

\section{ACKNOWLEDGMENT}

Special acknowledgments are given to late Associate Professor, Giannis Papadakis, who gave motive, shared comments and inspired this study

\section{REFERENCES}

[1] J. De-Sola Gutiérrez, F. Rodríguez de Fonseca, and G. Rubio, "CellPhone Addiction: A Review.," Front. psychiatry, vol. 7, p. 175, 2016.

[2] T. S. Lane, J. Armin, and J. S. Gordon, "Online Recruitment Methods for Web-Based and Mobile Health Studies: A Review of the Literature.," J. Med. Internet Res., vol. 17, no. 7, p. e183, Jul. 2015.

[3] Redelinghuys, "The use of interactive technology for effective teaching and learning in open distance learning programmes," 2017.

[4] M. N. Marshall, "Sampling for qualitative research," Fam. Pract., vol. 13, no. 6, pp. 522-526, Jan. 1996.

[5] E. Frøkjær, M. Hertzum, and K. Hornbæk, "Measuring usability," in Proceedings of the SIGCHI conference on Human factors in computing systems - CHI '00, 2000, pp. 345-352.

[6] F. F.-H. Nah, K. Siau, and H. Sheng, "The value of mobile applications," Commun. ACM, vol. 48, no. 2, pp. 85-90, Feb. 2005. 
[7] D. Wang, S. Park, and D. R. Fesenmaier, "The Role of Smartphones in Mediating the Touristic Experience," J. Travel Res., vol. 51, no. 4, pp. 371-387, Jul. 2012.

[8] J. Traxler, "Learning in a Mobile Age," Int. J. Mob. Blended Learn., vol. 1, no. 1, pp. 1-12, 2009.

[9] M. O. M. El-Hussein and J. C. Cronje, "Defining Mobile Learning in the Higher Education Landscape," Journal of Educational Technology \& Society, vol. 13. International Forum of Educational Technology \& Society, pp. 12-21, 2010

[10] N. Pachler, B. Bachmair, J. Cook, and G. R. Kress, Mobile learning: structures, agency, practices. Springer, 2010.

[11] K. L. Wilson, A. Lizzio, and P. Ramsden, "The development, validation, and application of the Course Experience Questionnaire,' Stud. High. Educ., vol. 22, no. 1, pp. 33-53, Jan. 1997.

[12] Yannis Tsantaridis, Sternes kai Piges tis Kerkiras. Athina: Ellinoekdotiki, 1997.

[13] M. Palmieri, I. Singh, and A. Cicchetti, "Comparison of crossplatform mobile development tools," in 2012 16th International Conference on Intelligence in Next Generation Networks, 2012, pp. 179-186.

[14] M. Nosrati, R. Karimi, and H. A. Hasanvand, "Mobile computing: principles, devices, and operating systems," World Appl. Program., vol. 2, no. 7, pp. 399-408, 2012.

[15] M. Arrington, "Google Redefines GPS Navigation Landscape: Google Maps Navigation for Android 2.0. TechCrunch,” 2009.

[16] David W. Wolber, App inventor: create your own Android apps. O’Reilly, 2011.

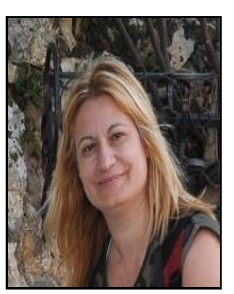

Eleni Moustaka holds a diploma in Computer Science (2010) obtained from Hellenic Open University of Patras, Greece. She also studied PSD in "Managing Items of Cultural Heritage and New Technologies" in Ionian University in Corfu, Greece and obtained her MSc degree in "Information Systems (2014) at the same university Her work experience is mainly related with accounting, tourism, and software technologies.

Published articles:

- Vasileios Komianos, Eleni Moustaka, Maria Andreou, Eirini Banou, Sofia Fanarioti, and Katia L. Kermanidis: "Predicting Personality Traits from Spontaneous Modern Greek Text: Overcoming the Barriers". AIAI
2012 Workshops, IFIP AICT 382, pp. 530-539, 2012.

- Evangelou, M. Moustaka, E. Moustaka: "The basic principles of the Stanislavski Method, which seem to greatly relate to the principles of event-based programming. As a case study, the electronic game creating software GameMaker is proposed". CIE 2014, pp 396-407, 2014.,

- E. Moustaka: "Seeking the past through the three-dimensional reality", Euromed 2017, pp 111, 2017.

Eleni's Moustaka research interests are related to 3D technology and mobile applications.

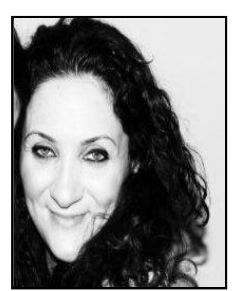

Dr. Antonia Plerou holds a Ph.D. degree obtained in the Department of Informatics of the Ionian University in Corfu. She studied Applied Mathematics at the Faculty of Sciences at the Aristotle University of Thessaloniki and obtained her Master Degree in Mathematics from the Faculty of Sciences and Technology of the Greek Open University. Her research focuses on the fields of Educational Neuroscience, Cognitive Science and Learning Difficulties (Dyscalculia, Algorithmic Thinking Difficulties), Neurofeedback Training, Neuronal Disorder rehabilitation with Neuroinformatics, and Artificial Intelligence.

She has (co) authored more than 30 articles in international conferences and journals and 2 book chapters. She is an editorial board member for several journals and she has been a program committee in numerous international conferences as well. Her research focuses on the fields of Educational Neuroscience, Cognitive Science and Learning Difficulties (Dyscalculia, Algorithmic Thinking Difficulties), Neurofeedback Training, Neuronal Disorders rehabilitation with Neuroinformatics, and Artificial Intelligence.

Dr. Antonia Plerou currently holds a university scholarship and she is teaching to undergraduate students of the Department of Informatics of the Ionian University. Moreover, she was a teaching stuff at M.Sc. Program "Bioinformatics and Neuroinformatics" of the Department of Informatics of the Ionian University and also advises almost 10 postgraduate theses on the same program. She is a member of the Bioinformatics and Human Electrophysiology Laboratory (BiheLab) of the Ionian University with the field of expertise "Pattern recognition analyst for Neuroeducational studies". 